\title{
Energy Recovery of the Biomass from Livestock Farms in Italy: The Case of Modena Province
}

\author{
Massimo Milani ${ }^{1}$, Luca Montorsi $^{* 2}$ \\ ${ }^{1}$ Department of Sciences and Methods for Engineering, University of Modena and Reggio Emilia, \\ Via Amendola 2 - Pad. Morselli, Reggio Emilia, Italy \\ e-mail: massimo.milani@unimore.it \\ ${ }^{2}$ Department of Sciences and Methods for Engineering, University of Modena and Reggio Emilia, \\ Via Amendola 2 - Pad. Morselli, Reggio Emilia, Italy \\ e-mail: luca.montorsi@unimore.it
}

Cite as: Milani, M., Montorsi, L., Energy Recovery of the Biomass from Livestock Farms in Italy: The Case of Modena Province, J. sustain. dev. energy water environ. syst., 6(3), pp 464-480, 2018, DOI: https://doi.org/10.13044/j.sdewes.d6.0199

\begin{abstract}
The overall energy conversion efficiency of the waste-to-energy technologies is strongly affected by the distance of the biomass supply and the rate available during the year. Therefore, a simulation tool for the evaluation of the main outputs of a power plant for the wastes exploitation is a useful instrument for investigating the best trade-off between the plant size and the biomass supply. Nevertheless, it usually involves a large number of data and an extensive training and expertise. This paper focuses on the development of a numerical tool for the comparison of different waste-to-energy technologies and thus supporting the selection of the best exploitation strategy based on the data usually accessible to administrations. The numerical approach employs validated numerical models for the considered biomass exploitation technologies and its capabilities are demonstrated by simulating a reference case: the energy recovery from manure of different livestock farms in the province of Modena (Italy). The electric and thermal power production from the manure available in the considered territory is estimated and the produced electric energy is balanced with the energy requirements of the local animal farms. The remaining amount of wastes that has to be disposed is also calculated and compared with the initial input to the systems. Finally, different strategies for distributed and centralized exploitation of the manure are investigated and the related plant size and production of electric and thermal energy are evaluated. The proposed approach and the developed numerical tool prove to be useful instruments for decision makers and can help the efficient exploitation of the biomasses available in a region.
\end{abstract}

\section{KEYWORDS}

Biomass, Waste-to-energy, Anaerobic digestion, Gasification, Water purification, Simulation.

\section{INTRODUCTION}

Due to the increasing awareness of the drawbacks regarding the use of fossil fuels, the attention towards renewable energy sources has increased substantially in recent years and particularly the viewpoint of waste management has changed from disposal to a

* Corresponding author 
possible energy resource [1]. Furthermore, the organic fraction of wastes in the form of municipal solid waste, sewage sludge, poultry litter, cattle manure and industrial effluents has been widely analysed for its use as renewable sources for energy. Different technologies are employed for the biomass exploitation, such as the anaerobic digestion [2] and gasification [3]. Many biomasses have been investigated for the energy conversion by means of the anaerobic digestion. Karagiannidis and Perkoulidis [4] analysed the energy recovery from the organic fraction of municipal solid wastes, while Pena et al. [5] investigated biogas production by means of swine wastewater digestion. Hadin and Eriksson [6] employed horse manure as feedstock for the anaerobic digestion and its methane potential was estimated. Dalólio et al. [7] reviewed the potential energy production from poultry litter. The manure from these animals can increase the biogas production from other biomasses such as cattle manure [8]. Furthermore, the energy recovery from biomass exploitation through anaerobic digestion can be enhanced by employing the digestate as an input for the gasification process [9] as an alternative to the direct gasification of the manure [10].

Benefits from the Waste-To-Energy (WTE) technologies for the organic fraction can be derived not only in terms of power production, but also in terms of Greenhouse Gases (GHG) reduction [11]. Combined cycles can further improve the power production from manure-based biogas and thus reduce the environmental impact [12]. The positive effects on emission mitigation can be proved also when comparing the energy exploitation of manure with the land application [13]. In addition, the use of animal manure as a bioenergy source determines advantages for the rural communities that can diversify the incomes, moderating the impacts of commodity prices, and securing the local energy demands [14].

Despite the benefits that WTE technologies can offer both in terms of power production and emissions reduction, the application of bioenergy systems encounters many barriers due to the amount and complexity of information relating to the development of such systems [15]. At the level of technology design assessment, the access to information about bioenergy systems and best practices for biomass production, harvesting and conversion appears to be complex as well as the manipulation of the data and specifications of different systems for the decision on the best technology for local biomass exploitation [16].

Simulation programs are a possible solution for supporting the decision making, creating strategies and procedures and forming policy [17]. Also different decision support methods can be employed involving both direct calculation and statistical evaluation [18]. Nevertheless, numerical modelling usually involves a large number of data that must be available and their implementation requires an extensive training and expertise. In Bottazzi et al. [19] a detailed numerical model of a coffee roaster plant was constructed for estimating the energy efficiency of different configurations of the systems, Dutra et al. [20] simulated different operations of a full cogeneration plant with a micro gas turbine. Anaerobic digestion systems have also been modelled on a full scale [21] in order to calculate the power production. These approaches demonstrated to be very accurate in providing the user with detailed results concerning the performance of the considered systems. Nonetheless, the complexity of the modelling makes these numerical tools exploitable only by expert users and the time necessary for the model set-up and execution is considerable [22].

This paper focuses on the development of a numerical tool for the comparison of different WTE technologies and thus supporting the selection of the best exploitation strategy when specific kinds of biomass are available. In particular, using the proposed tool the effects of the combination of three WTE technologies in one bioenergy system are evaluated, such as anaerobic digestion, gasification and incineration [23]. The performance of the considered processes is calculated on the basis of the numerical 
models described in [24], while a Java Graphical User Interface (GUI) is developed in order to create a user friendly interface that can be employed by people with no expertise in coding or software creation.

The in-house developed software aims at helping the decision makers determine the possibility of taking advantage efficiently of the wastes available in a territory and investigate different scenarios accounting for the available biomass rate and confronting different sizes of the system and relating supply distances. The capabilities of this numerical approach are addressed by simulating a reference case being the energy recovery from manure of the Italian livestock farms located in the province of Modena. In the analysis, anaerobic digestion and gasification are accounted for and the manure from different types of animals is also considered. The reference bioenergy system includes an anaerobic digester, a downdraft gasifier and water treatment for the liquid part of the digested sludge. The obtained bio-gas and syngas are used in a cogeneration system based on an internal combustion engine to produce electric and thermal power.

The potential electric power production of the considered territory is calculated for a number of different scenarios and the produced electric energy is compared with the energy requirements of the local animal farms. Furthermore, the amount of final wastes that still have to be disposed is evaluated and the reduction with respect to the initial input to the system is highlighted. In particular, the distributed exploitation of the manure versus a centralized solution is investigated in terms of plant size and electric and thermal energy production. Finally, the capabilities of the proposed approach and the developed numerical tool as an instrument for decision makers are assessed.

\section{MATERIALS AND METHODS}

An in-house software is developed in order to help the decision makers determine the possibility of exploiting the wastes available in a territory and investigate different scenarios depending on the available biomass rates and supply distances. The simulation tool includes the prediction capabilities of detailed numerical models for anaerobic digestion, gasification and combustion of biomass in an easy to use GUI. The aim of the code is to create a platform for the simulation of different scenarios of WTE technologies for the exploitation of a given biomass composition. The numerical models for the simulation of the performance of the considered biomass conversion processes are described in [25]. In the following, the focus is devoted to the interface created for enabling a flexible and user friendly utilization of these numerical models. In fact, the developed Biomass Management Tool (BMT) is intended not only for experts in the numerical modelling, but for supporting the decision making, creating strategies and procedures and forming policy. Thus, the aim of the work is bridging the gap between the amount of information needed for the evaluation of the bioenergy systems and the performance prediction of each system.

The adopted coding language is Java [25], due to its capabilities in handling GUI elements and the possibility of creating routines with the mathematical models of the biomass conversion processes accounted for in the analysis.

Figure 1 shows the main page of the software and along with the usual tools for files and windows handling. The different sections of the current project can be accessed on the panel at the left hand side. The sections include the setting of the "Scenario" conditions, such as the biomass input, the preliminary screening of the energy conversion efficiency of the modelled WTE technologies applied to the input biomass, and the "Engineering" results detailing the performance of the bioenergy systems that the user intends to investigate. Future work will be devoted to implement "Economics" and "Management" sections to include in the analysis parameters for the evaluation of the investment and constraints relating the logistics of the energy systems. These functionalities will allow the user to set constraints and merit indexes in order to automatically define the optimal strategy for the 
plants' size and siting on the basis of a multi-objective optimization analysis, accounting for features such as the maximum distance of the biomass supply chain, the maximum area occupied by the plant, the economies of scale and the return on investment. Figure 2 depicts the panel for the biomass input and as an example the animal wastes are in foreground, but vegetable wastes and the desired composition of the Municipal Solid Wastes (MSW) can be evaluated in the analysis as well.

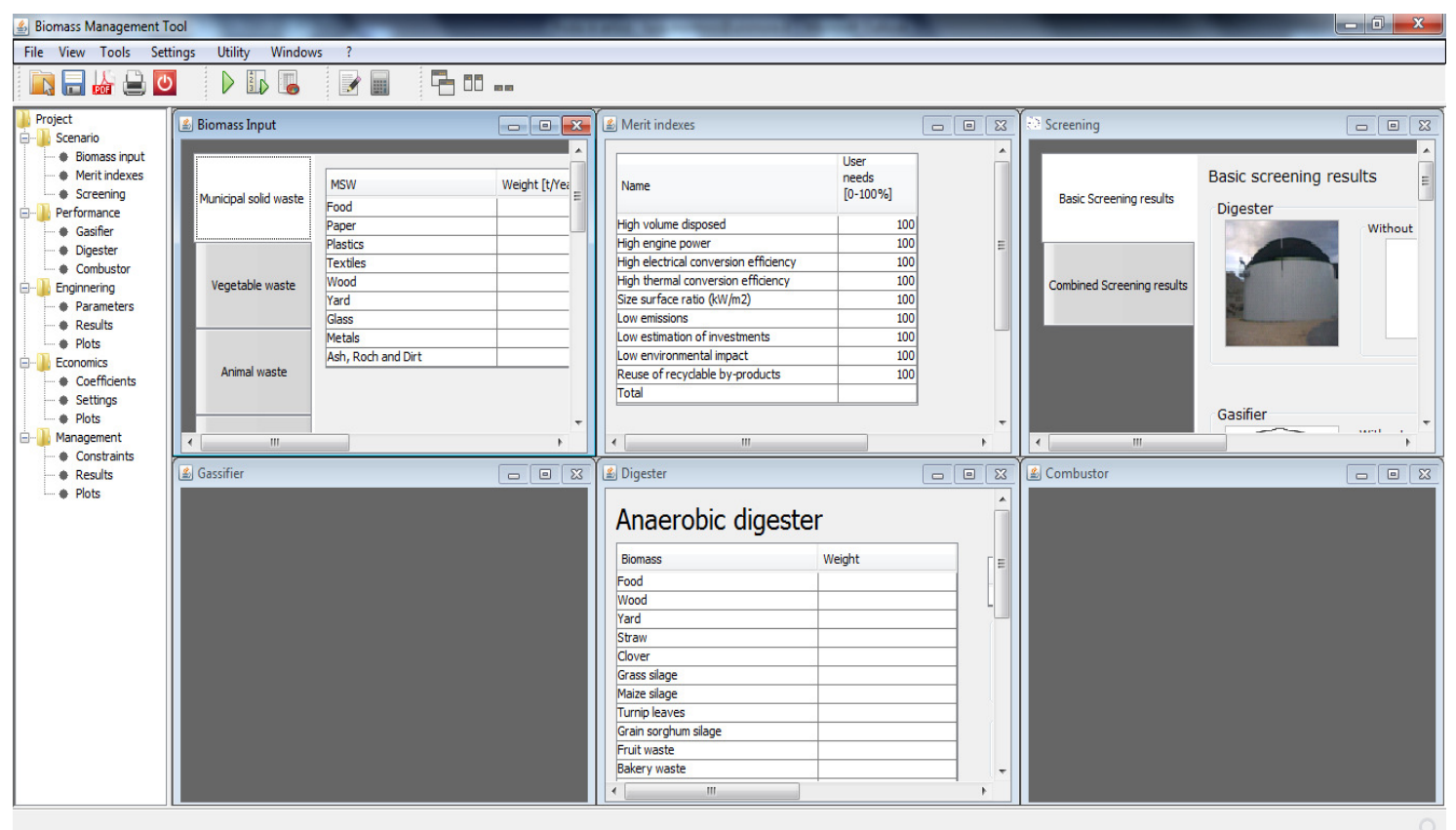

Figure 1. Main screen of the BMT software

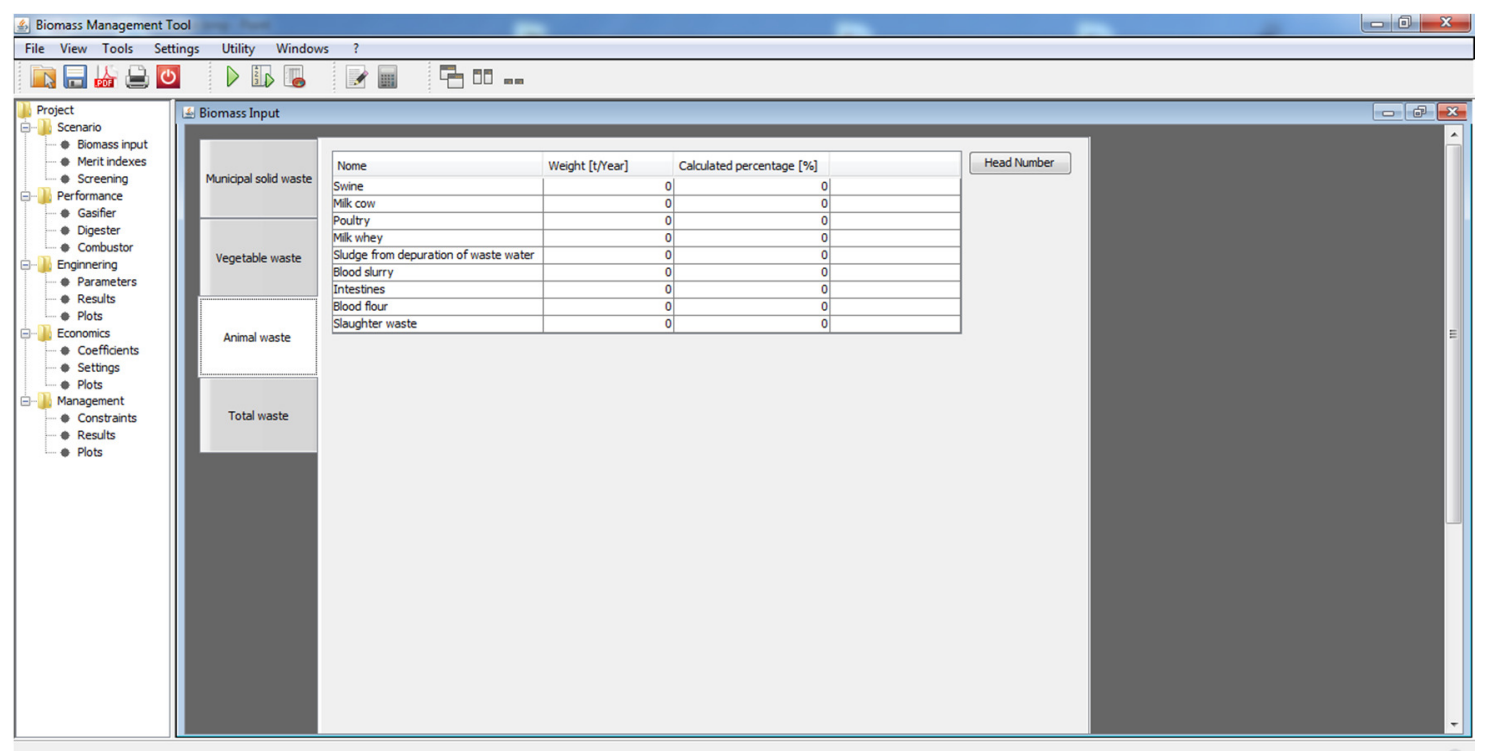

Figure 2. Main screen of the BMT software: focus on the input biomass for animal wastes

Each biomass amount can be set either in terms of percentage of the overall total or in terms of tonnes per year available. When applicable, the number of heads of the selected animals can be also used as an input and the corresponding annual manure production is calculated. Furthermore, a summary of all the biomasses employed in the simulation is provided in order to have a complete overview of the input conditions and eventually modify them. In the BMT code 42 species of biomass are considered. First data 
processing is the preliminary screening of the main WTE technologies in order to address the overall efficiency of the different processes for the exploitation of the input biomasses, see Figure 3. The preliminary screening is the result of a rough estimation of the efficiency of the anaerobic digestion, gasification and combustion when using the selected biomass as an input. The suitability of each process is visualized using three symbols that at a glance show if the three considered bioenergy systems could be effectively adopted for the energy conversion of the input biomass composition. Eventually the use of a biomass separation pretreatment is also accounted for and a suitability evaluation is also given in the case of biomasses that are separated according to their water content and the relating most befitting WTE technology. The preliminary screening section includes also a second panel that can be used for detailing slightly further the basic suitability analysis, see Figure 4.

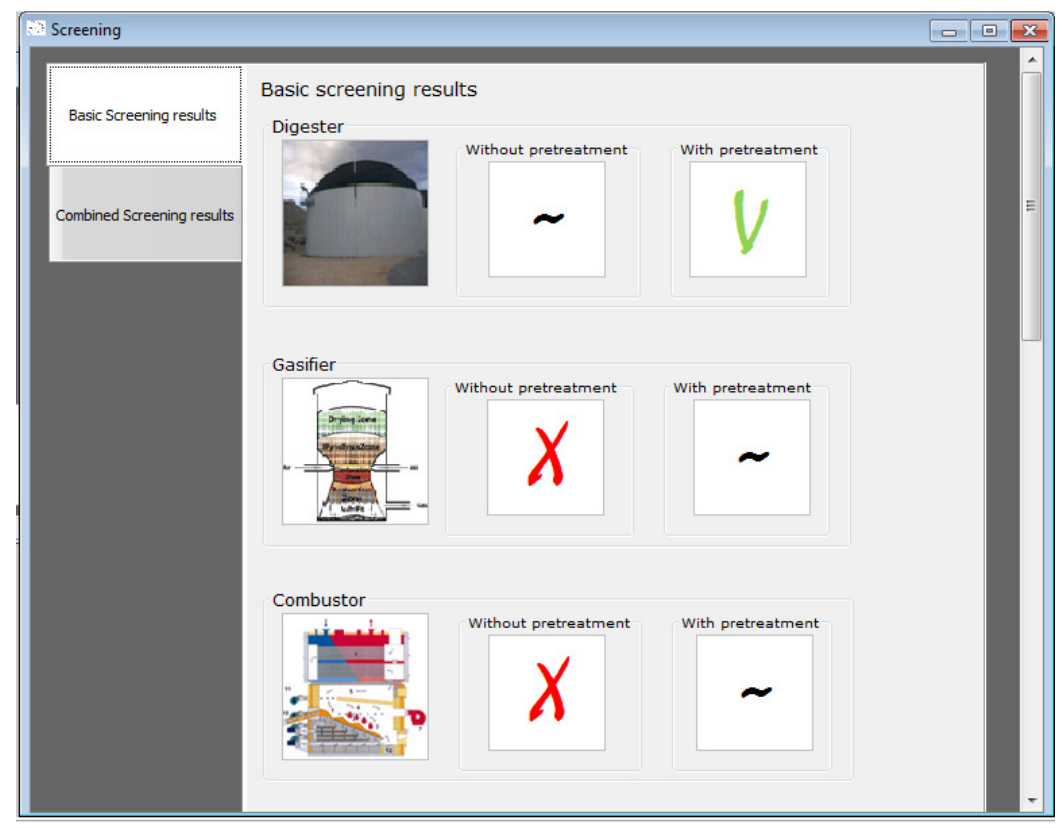

Figure 3. Panel for a preliminary screening of the results from the considered WTE technologies

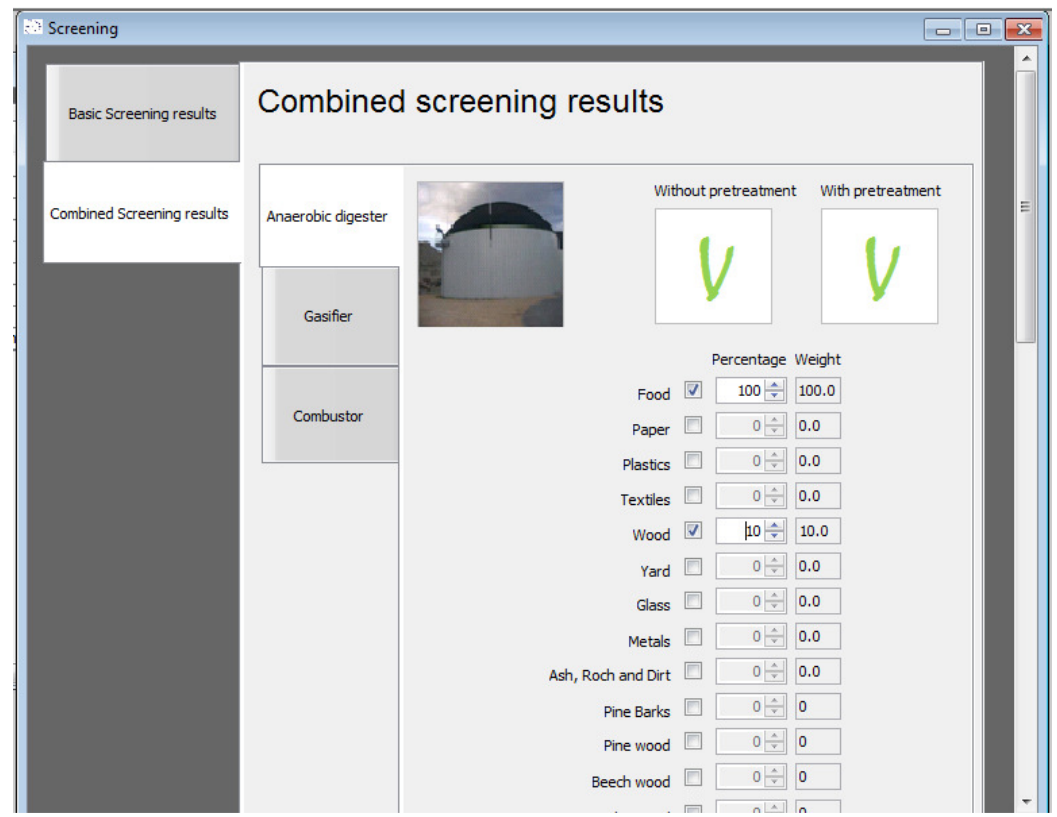

Figure 4. Panel for selecting a fraction of the input biomasses for the preliminary screening of the results from the different WTE technologies (case of the anaerobic digester) 
Using this option, the screening is subdivided for each considered process and the input biomasses can be directed to the different WTE technologies by selecting the proper fraction for each energy conversion system. If a biomass is clearly not suitable for the analysed process, its fraction can be set to null and thus that biomass will be disregarded in the preliminary efficiency evaluation of that system for the exploitation of the input biomasses.

In addition, the preliminary screening of the main WTE processes can be influenced by means of a set of merit indexes implemented in the code. Figure 5 lists the considered merit indexes and the default value is set to $100 \%$ for all of them. If one or more indexes correspond to particularly important constraints for the analysed case study, the merit values can be modified accordingly and their weight in the calculation of the suitability of the selected processes will be affecting the symbols displayed in the panels of Figures 3 and 4.

Finally, the performance results of each WTE technology are plotted in a separate window, see Figure 6. In the results panel, the biomasses exploited in the considered energy system are reported along with the daily and annual production of biofuel (i.e., biogas or syngas) and the electric energy production (i.e. electric power and energy produced per year). An important parameter that can be set in this panel is the annual operating time, the value can be different for the three considered bioenergy systems and it influences the size of the plant that can process the input biomass rate.

The accuracy of the results is dependent on the numerical models adopted for the simulation of the considered processes for the exploitation of the several biomasses. More details concerning the validation of the numerical results can be found in [24].

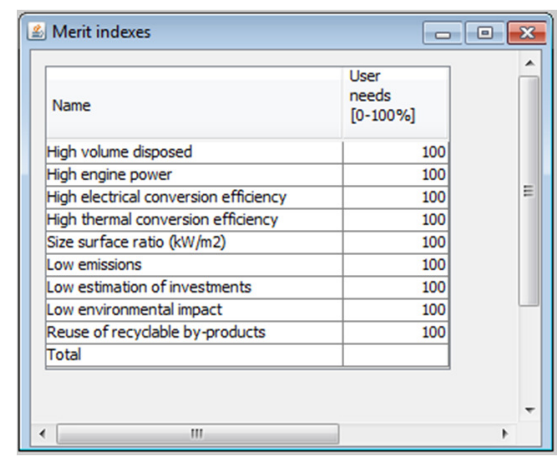

Figure 5. Considered merit indexes for the preliminary screening

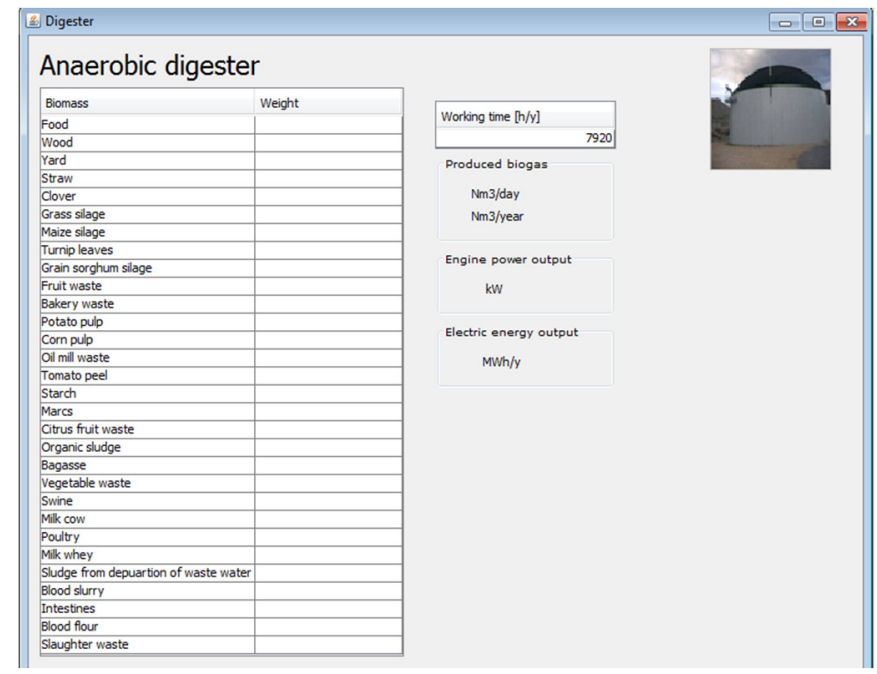

Figure 6. Panel with the report of the main performance parameters of each WTE technology (case of the anaerobic digester) 
In order to evaluate the capabilities of the proposed approach and the developed numerical tool as an instrument for decision makers a reference test case is analysed and different scenarios are compared. In particular, the manure available from the animal farming in the province of Modena in Italy is taken into account and the potential application of an integrated anaerobic-digestion - gasification - water treatment system is investigated.

According to the Italian regulation, the manure from livestock farms is considered as a waste that can be used as a fertilizer or disposed to landfill. The province is subdivided into 47 municipalities, see Figure 7, where animal farming plays an important role on the local economy. The farms focus mainly on the families listed in Table 1 and the total number of heads is significant, particularly for pigs and cows. The relating amount of manure is therefore remarkable and it is usually employed as fertilizer in agriculture or disposed in landfill when it exceeds the limit to be spread on the soil.

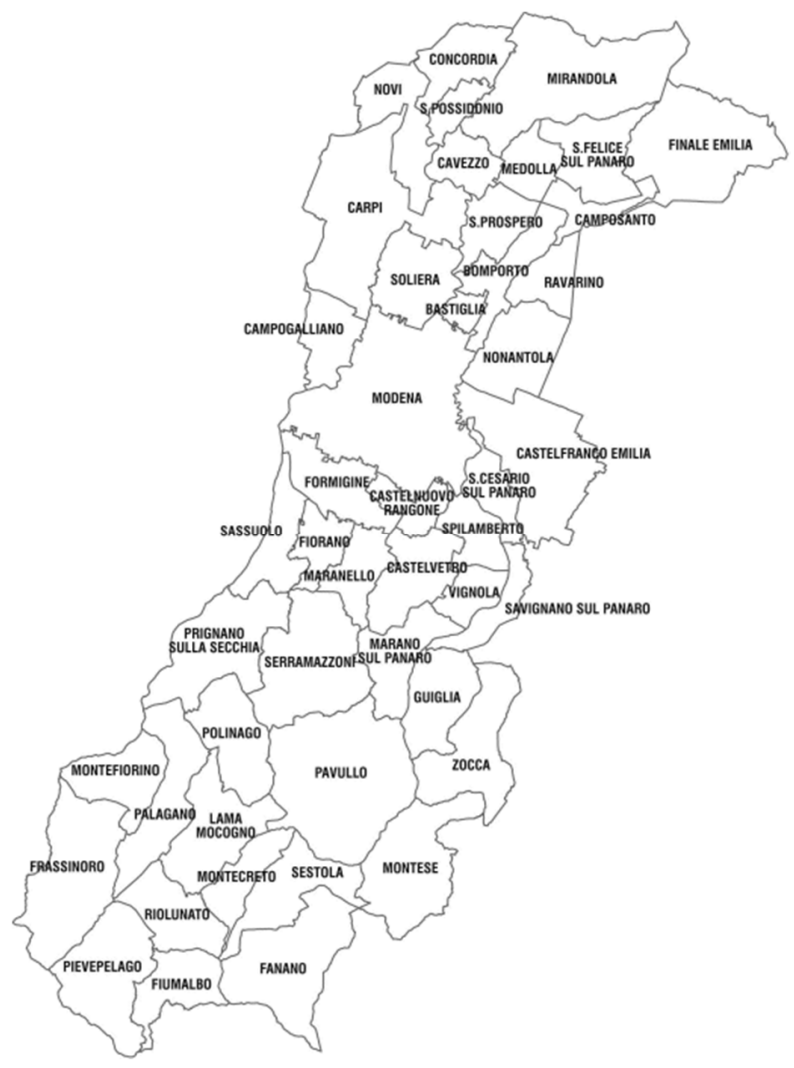

Figure 7. Map of the Province of Modena showing the subdivision in its municipalities

Anaerobic digestion is likely one of the most promising WTE technologies for exploiting the manure from the different animal farms. In order to evaluate the electric energy that could be produced by the biogas from the manure in the province of Modena, the annual manure produced by the total number of heads as detailed in Table 1 is adopted as an input in the BMT code.

In order to minimize the final wastes remaining, an integrated approach for the exploitation of the initial biomass is analysed, the plant includes the following processes: anaerobic digestion, gasification and water treatment. The employment of the three processes enables to maximize the exploitation of the biomass and to reduce the remaining amount of waste, thus it is possible to improve the total energy conversion efficiency of the system calculated on the basis of the initial energy content of each adopted biomass. Figure 8 shows the layout of the proposed integrated plant. First, the manure from the considered animals enters the anaerobic digester and is converted into biogas, then, after the time period necessary for the bacterial reactions to take place, the biological sludge from the 
digester is extracted (dash-dotted line) and subdivided into its liquid and solid part. The solid part is dried using the heat from the co-generation unit and is employed as the biomass for the gasification process (dotted line). Conversely, the liquid part is treated in the water purification process and demineralized water is obtained along with the residues that have to be disposed of or used as fertilizer. Before storing the syngas and the biogas (dashed line) in the tank, a gas treatment system is adopted, including filtration, cooling and desulfurization.

Table 1. Total number of heads for each considered animal family in the Province of Modena (data at the end of 2011)

\begin{tabular}{ccc}
\hline Family & Total heads & {$[\%]$} \\
\hline Swine & 295,623 & 68.3 \\
Ovine & 5,489 & 1.3 \\
Poultry & 33,250 & 7.7 \\
Horse & 4,742 & 1.1 \\
Bovine & 94,012 & 21.7 \\
\hline
\end{tabular}

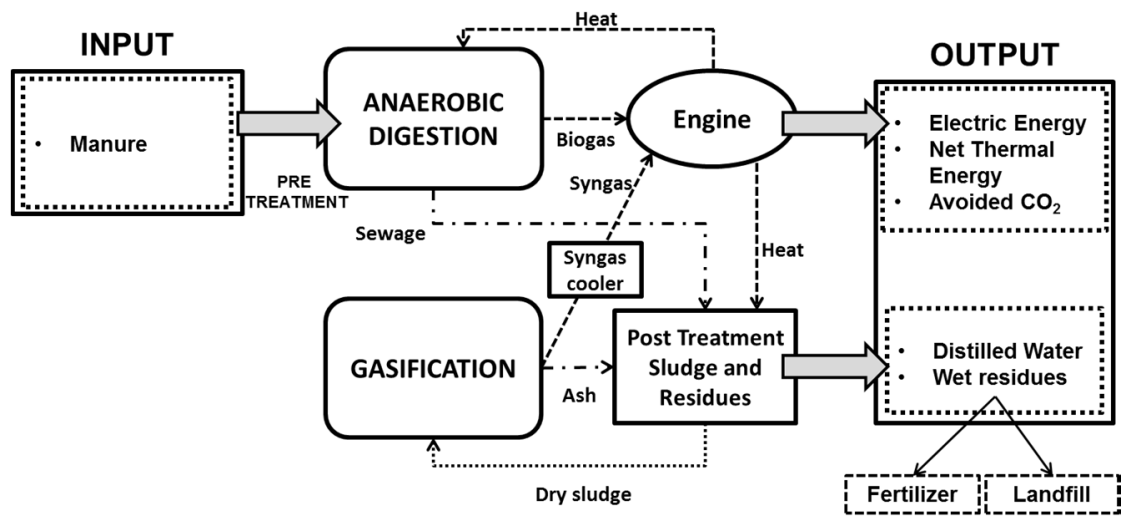

Figure 8. Layout of the considered integrated plant

The purified gas is then used as fuel in a spark ignition Internal Combustion Engine (ICE). An alternator connected with the ICE produces electrical energy while the heat exchanged at high and low temperature is used for self-sustenance operations of the plant such as the heating of the anaerobic digester or the biological sludge drying. The liquid fraction of the biological sludge is finally converted into distilled water and in an ammonia solution after micro, ultra and nano-filtration and finally forward/reverse osmosis treatments.

Gasifier humid slag and the solid part of the filtration can be used as fertilizer or disposed to landfill according to the local regulation.

\section{RESULTS AND DISCUSSION}

In the following, the main results that can be obtained by means of the BMT code are presented and the potential of the exploitation of the manure from the animal farming in the province of Modena in Italy is discussed.

First scenario that is taken into account considers each municipality of the province separately and the performance of a single integrated plant exploiting all the manure from that district is analysed. This scenario represents a distributed case of energy production from the manure of the provincial area. Figure 9 plots the electric power generation from the supposed 47 plants and the contribution of the biogas and syngas to the total production. It can be noticed that in several municipalities the size of the potential integrated plant is remarkable and 8 systems result larger than $1 \mathrm{MW}$. On the other hand, many bioenergy systems are characterized by very small sizes and 10 plants have an electric power output close to or smaller than $100 \mathrm{~kW}$. 
The effectiveness of the integrated anaerobic digestion and gasification conversion system is outlined in Figure 10. In fact, the exploitation of the solid part of the digested manure in the gasifier contributes for approximately the $20 \%$ of the total power production.

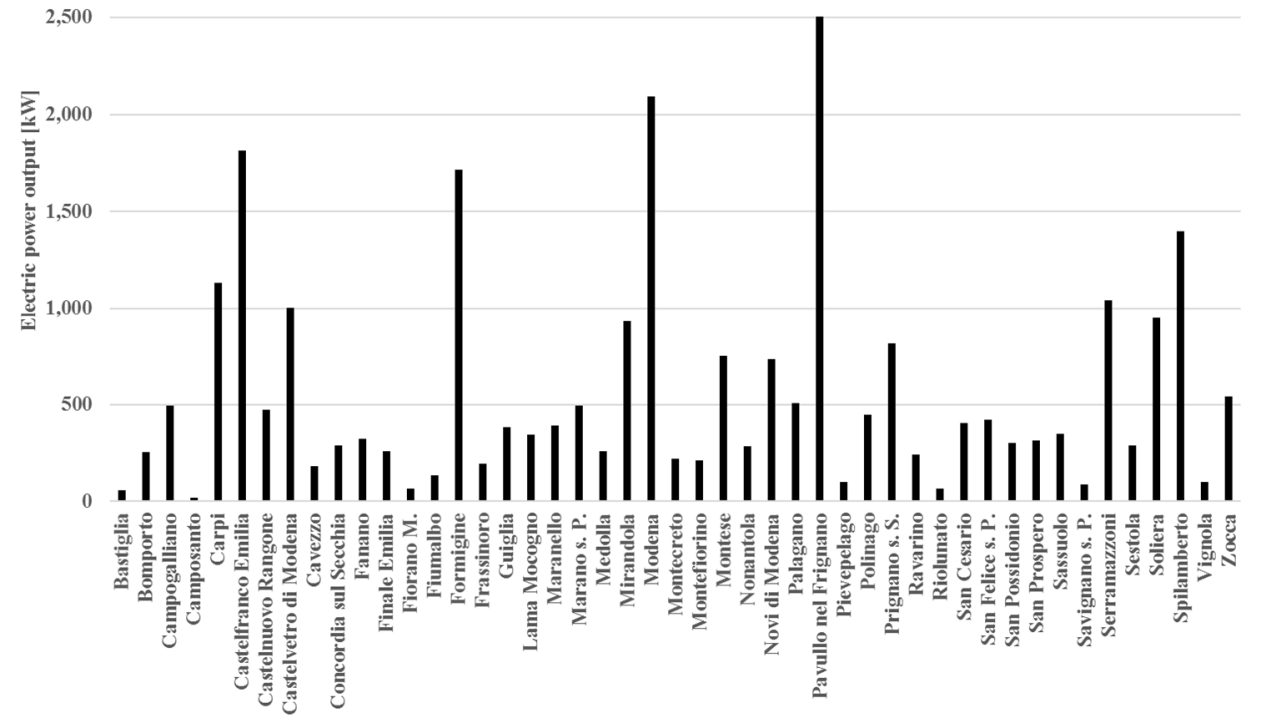

Figure 9. Electric power output of the integrated plants exploiting the manure from all the considered animal families for each municipality

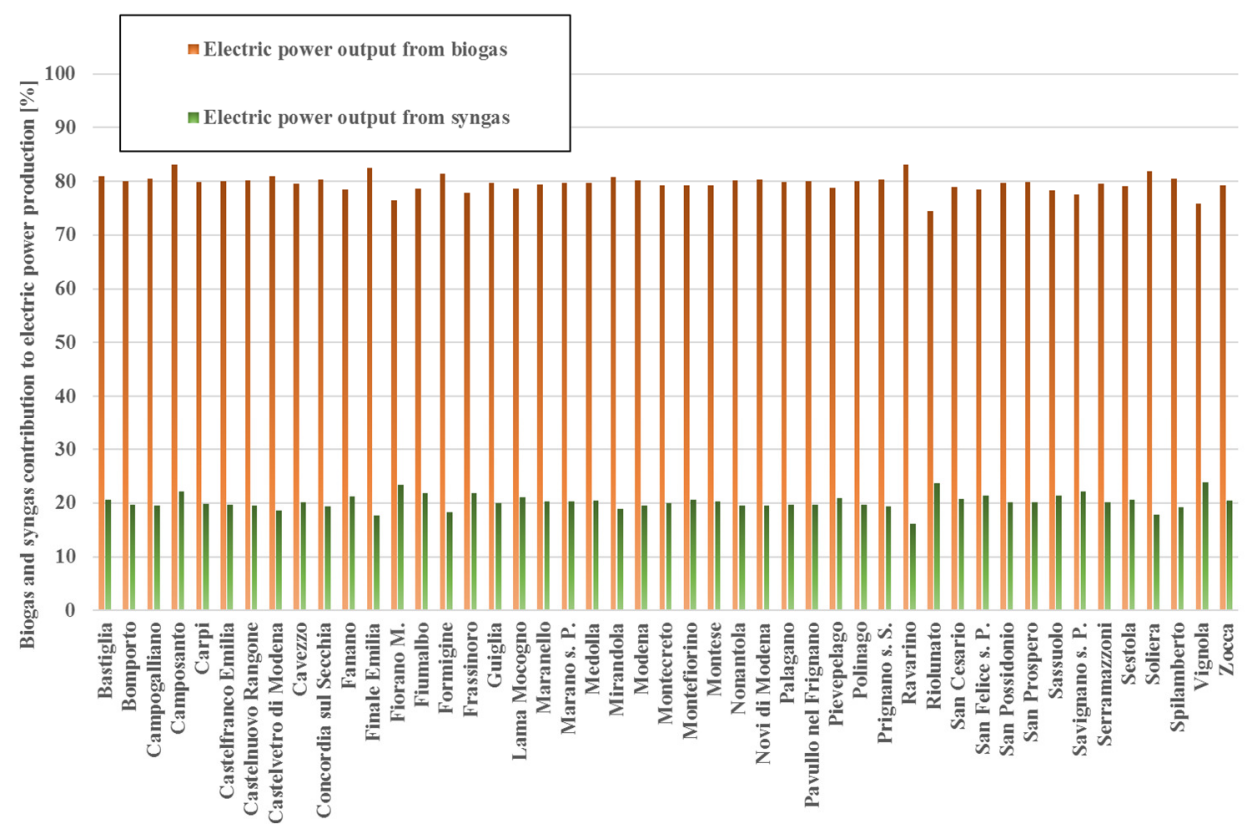

Figure 10. Biogas and syngas contribution to the total electric power production for the integrated plants exploiting the manure from all the considered animal families for each municipality

The differences in the biogas and syngas contribution to the electric energy produced is due to the difference in input composition of the integrated plant as a consequence of the number of heads of swine, bovine, horse, ovine and poultry of the considered municipality.

For the calculation of the annual production of electric energy, a working period of the plant equal to 7,200 hours is considered. By summing the electric power production 
of all plants, an annual electric energy output of approximately 190.04 GWh is predicted. This value is remarkable, in particular when compared to the energy requirement per year of the whole agricultural sector of the province of Modena, see Figure 11. In fact, by exploiting the manure of the provincial animal farming, the resulting electric energy production exceeds greatly the needs of the agricultural industry (i.e. 195.7\%).

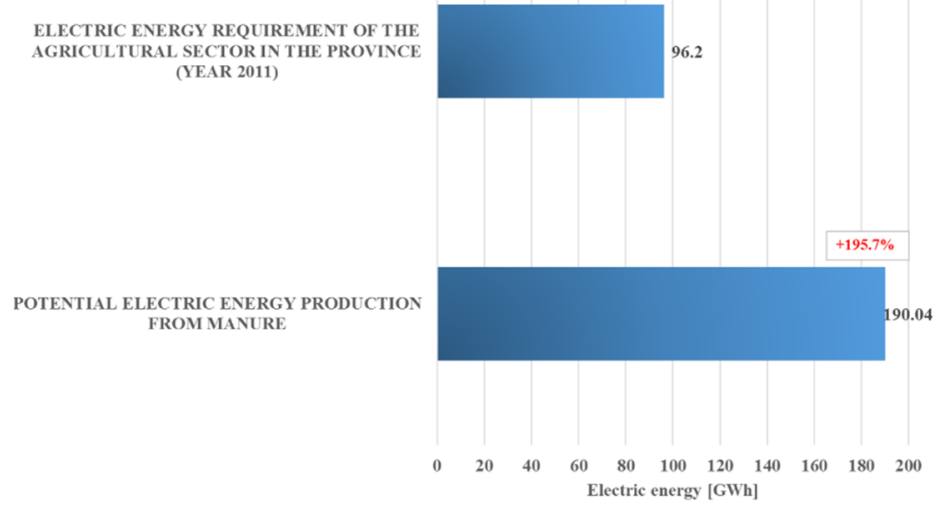

Figure 11. Comparison between the potential annual electric energy production from the manure of all the considered animal families for all municipalities and the electric energy requirement of the whole agricultural sector in the province of Modena in 2011

The BMT code takes also the thermal power production into account. Figure 12 depicts the total thermal production of the 47 integrated plants and compares it to the net thermal power output of the systems. The latter values are calculated by subtracting from the total thermal power available at the internal combustion engine co-generation system the amount needed both for heating the anaerobic digestion reactor and for the drying process of the separated solid part of the digester sludge. In fact, these two contributions are not negligible and indeed amount to a large part of the heat recovered from the engine. In a few districts characterized by very small size plants the heat by the Combined Heat and Power (CHP) system is very close to the amount required to sustain the digester temperature and the sludge drying process.

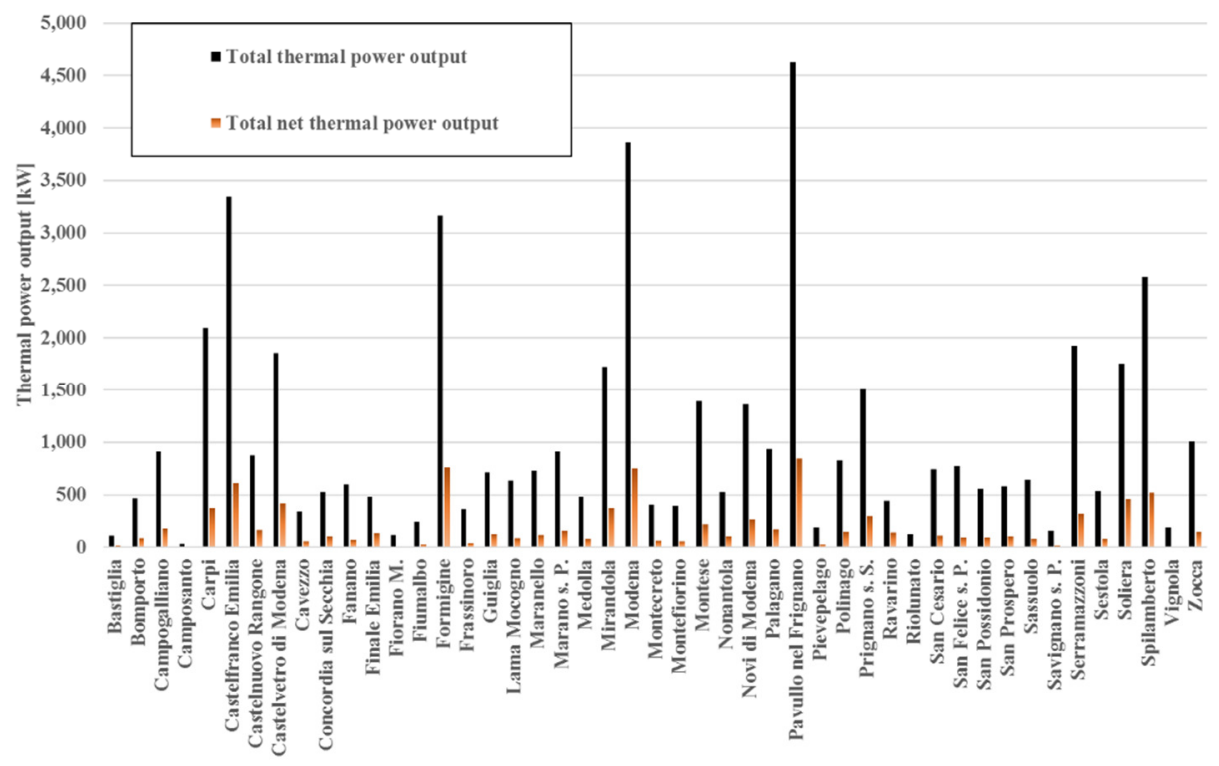

Figure 12. The thermal power output of the integrated plant exploiting the manure from all the considered animal families for each municipality 
Figure 13 highlights two important features of the bioenergy system such as the avoided emission of Carbon dioxide $\left(\mathrm{CO}_{2}\right)$ and the production of purified water. The avoided $\mathrm{CO}_{2}$ is calculated by considering the carbon emission of a fossil fuel used for the production of the same amount of electric energy. The total saving in terms of $\mathrm{CO}_{2}$ emission for all 47 plants reaches almost 300,000 t/y, while the purified water available for the district water piping is up to 115 million litres. Furthermore, Figure 14 compares the total biomass input to the considered plants and the remaining wastes to be disposed either as a fertilizer or to landfill. Depending on the initial composition of the manure exploited in each bioenergy system, the remaining amount of waste ranges from 3 to $6 \%$, this result demonstrates the high efficiency of the integrated approach to the exploitation of the manure from the considered animal families.

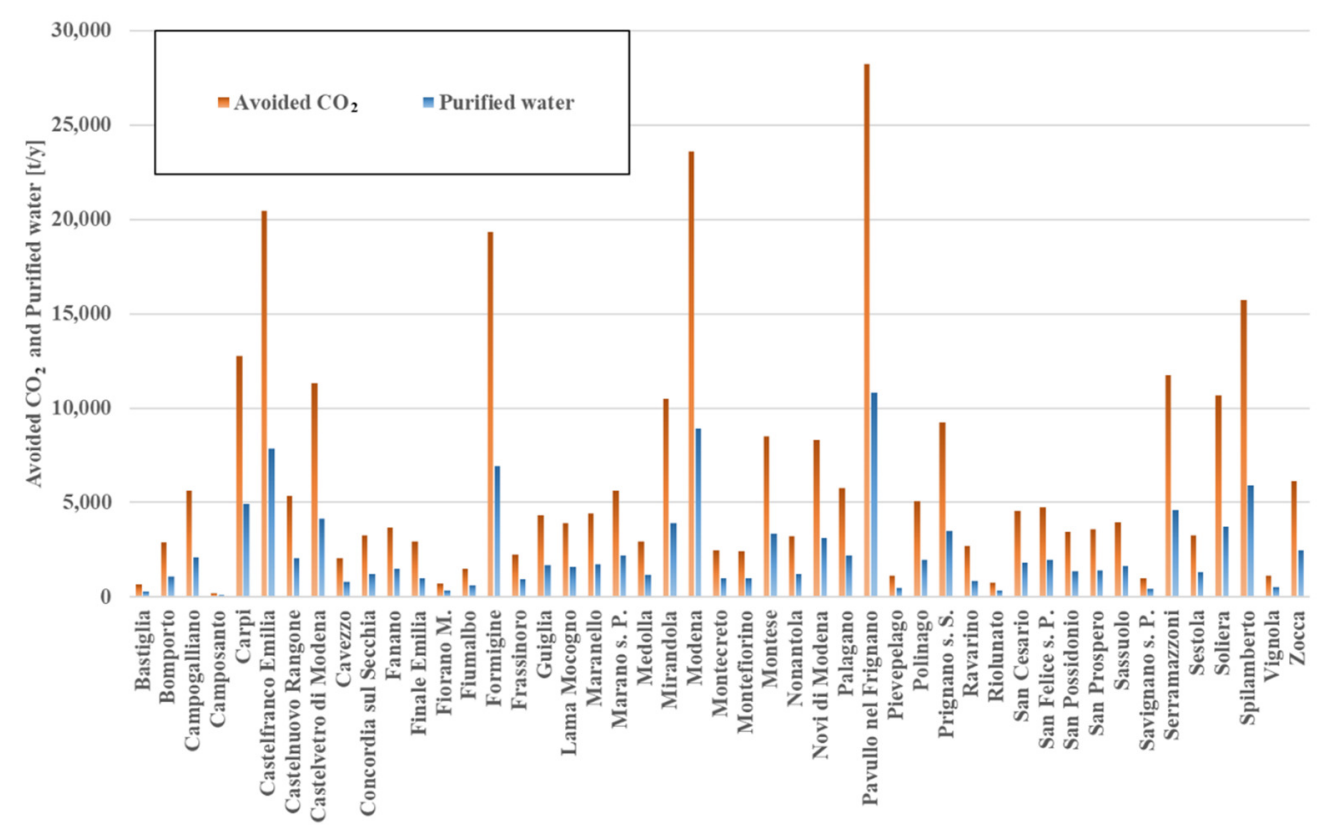

Figure 13. Avoided $\mathrm{CO}_{2}$ and purified water production of the integrated plant exploiting the manure from all the considered animal families for each municipality

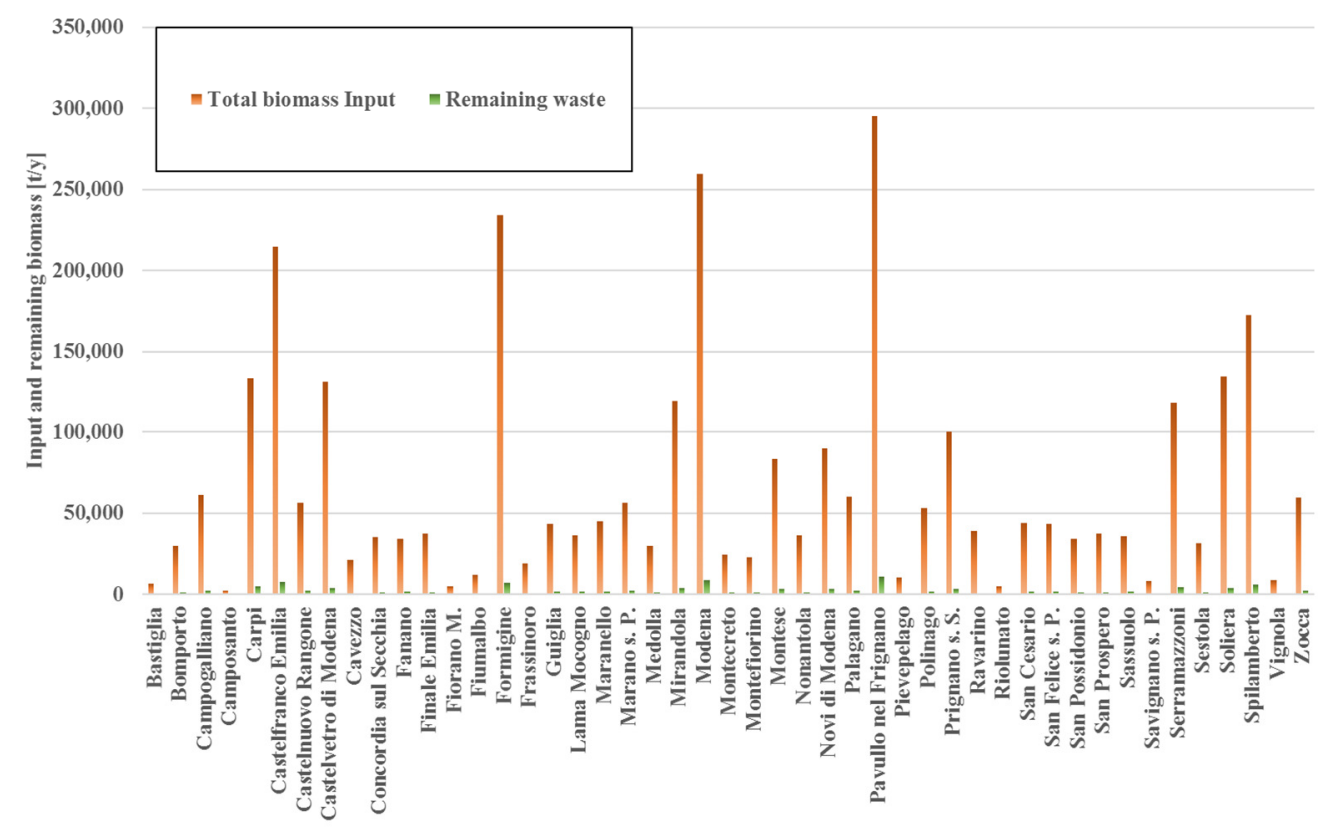

Figure 14. Total biomass input and remaining waste of the integrated plant exploiting the manure from all the considered animal families for each municipality 
A second scenario of distributed exploitation of the manure from the animal farming of the province is considered by assuming a different plant both for each municipality and for manure of each animal family. This example represents the most distributed case of energy production and it is useful to address the contribution of the different animal families in the power production from manure.

Figure 15 reports the total electric power output of the integrated plant exploiting the manure from the different animal families for each municipality. As expected by comparing the heads number of the animal families listed in Table 1, the manure from pigs and cows provides the largest contribution to the electrical energy output of the considered plants, see Figure 16 . The bovines cover approximately the $21 \%$ of the heads in the province while they can potentially provide $70 \%$ of the electric energy recovered from the manure, conversely the swine heads are almost the $70 \%$ of the total amount of animals raised in the province and produce the $20 \%$ of the electric power output. On the other hand, even though the poultry heads are a large number, i.e., 7.7\% of the entire population, the potential energy output is rather low when compared to the other animal families. This result can be observed also in terms of size of the plants for the 47 municipalities. The size of the single plant for each district, i.e., the first scenario, is similar to the sum of the size of the plant for bovine manure and the size of the swine manure one. A few exceptions can be outlined for the municipalities where large farms of different animal families are located. Similar considerations can be made when addressing the net thermal power output of the integrated plant exploiting the manure from the different animal families for each municipality, see Figure 17. Due to the very small size of some the plants, the heat by the CHP system is not enough to sustain the digester temperature and the sludge drying process. This second scenario is useful to investigate the contribution of the manure from the different animals' families to the energy that can be recovered from the wastes of the animal farming sector but it is characterized by critical aspects that suggest exploiting the manure following a different strategy.

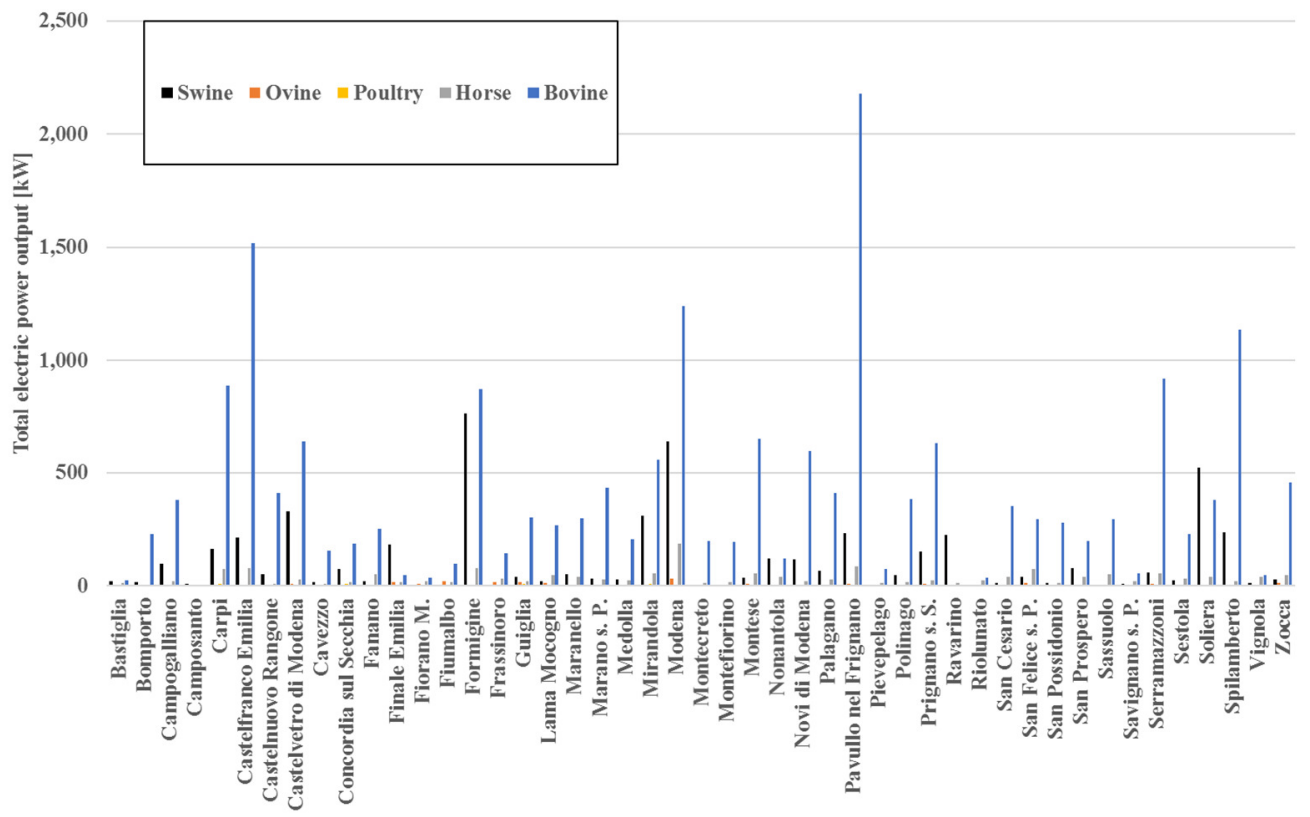

Figure 15. Total electric power output of the integrated plant exploiting the manure from the different animal families for each municipality

In the third scenario, the municipalities of the province of Modena are grouped considering the adjoining districts and the results obtained in the scenarios analysed previously. Thus, 20 groups are formed and the bioenergy systems exploiting the manure 
from the districts of each group are investigated, see Figure 18. The main guidelines adopted for creating the 20 areas are the proximity and the resulting size of the plant. The first criterion is used in order to minimize the effects of transportation on the biomass supply costs as well as the $\mathrm{CO}_{2}$ emission due to the vehicles. Thus, each area is characterized by a maximum radius of $20 \mathrm{~km}$ from its centre. Secondly, the aim of the partition of the municipalities is obtaining an average plant size close to $1 \mathrm{MW}$ in terms of electric power output. Figure 19 shows that this target is reached for almost all areas, the only exception is the group \#19 which is located in the highest part of the mountain Apennines of the province of Modena. In this case, the first criterion is considered more stringent than the plant size due to the characteristics of the territory which make the transportation more difficult. Nevertheless, the electric power output of this plant is not negligible and it is close to $0.5 \mathrm{MW}$, similarly, the net thermal power output is positive, thus the bioenergy systems recover enough heat to sustain the processes on the integrated plant.

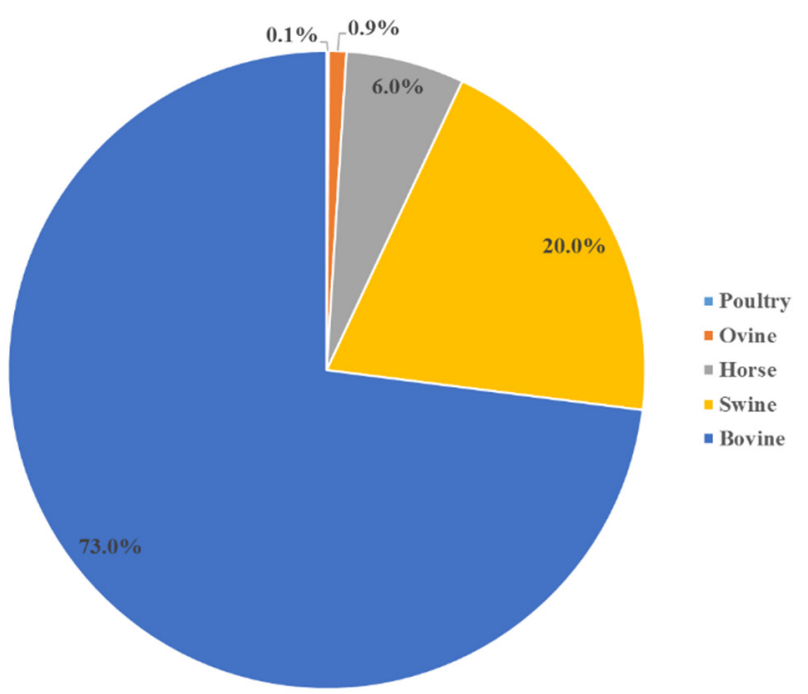

Figure 16. Contribution of the manure from the different animal families to total electric power production

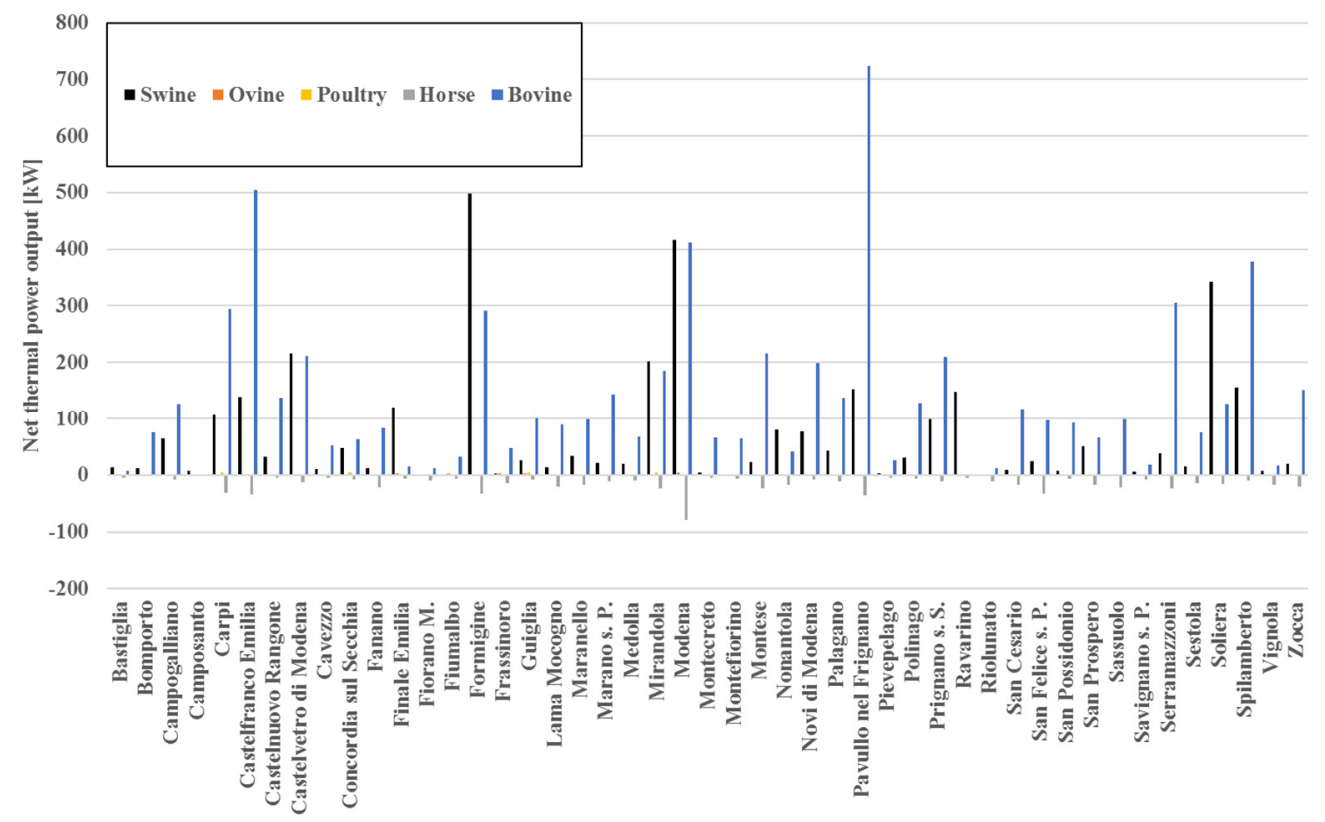

Figure 17. Net thermal power output of the integrated plant exploiting the manure from the different animal families for each municipality 


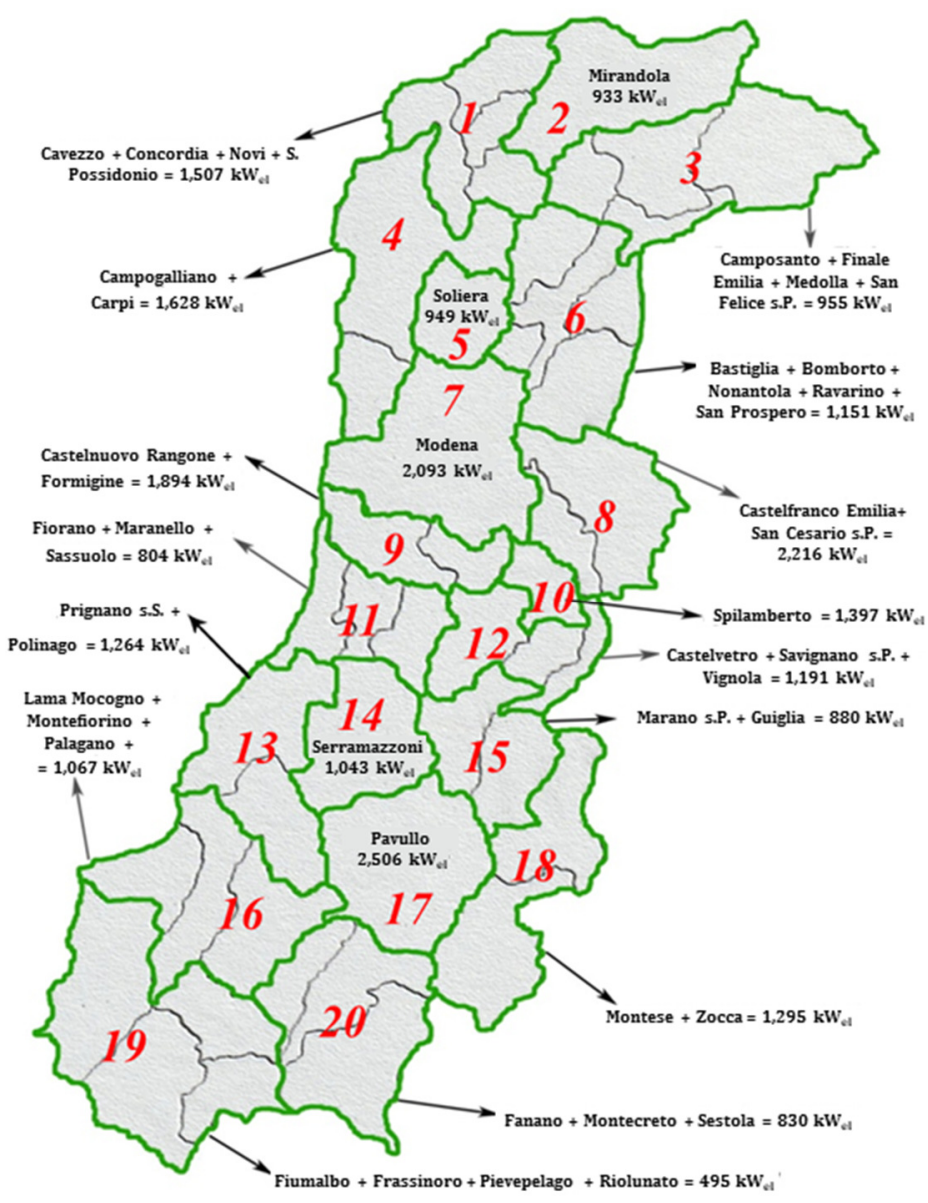

Figure 18. Centralized exploitation of the manure in groups of adjoining municipalities

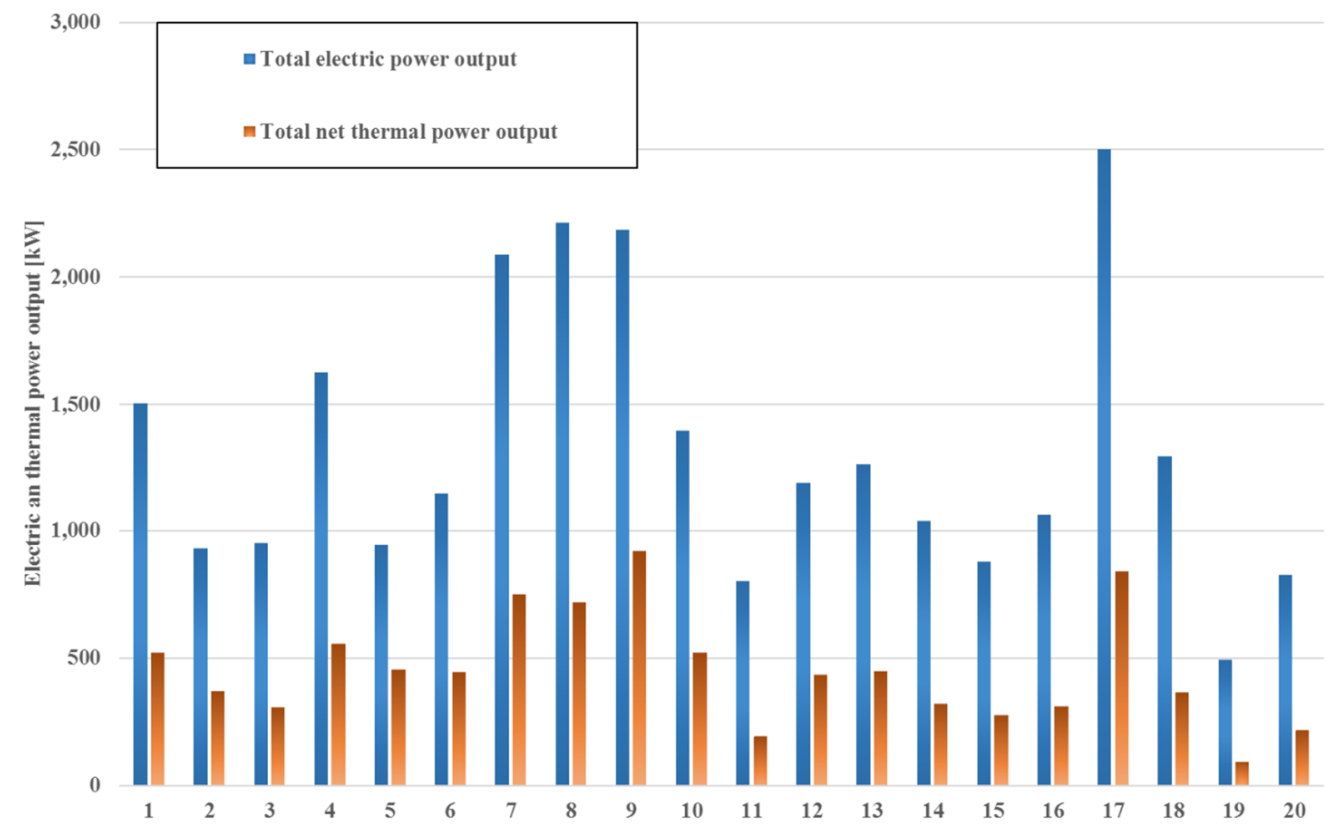

Figure 19. Electric and thermal power output of the integrated plants exploiting the manure from all the considered animal families for each group of municipalities

On the other hand, 4 plants result in larger than the reference size. In particular, the areas \#7, \#8 and \#9 are characterized by an electric power output of more than $2 \mathrm{MW}$ and the three areas include a total number of 5 municipalities. In fact, this zone of the province is where a very high concentration of animal farms can be observed and a 
further subdivision of the manure supply chain should refer to the locations of each farm rather than the whole municipality.

Similar consideration can be drawn for area \#17, which includes only one municipality characterized by a very large amount of animals farmed.

\section{CONCLUSIONS}

The paper focuses on the development of a new numerical tool for the evaluation of different WTE technologies, in particular, anaerobic digestion, gasification and incineration are accounted for in the code and a number of biomasses can be selected as an input to the bioenergy systems. The tool aims at creating a platform for the simulation of different scenarios of WTE processes for the exploitation of a given biomass composition. The considered biomasses included vegetable and animal wastes as well as the fractions of the MSW. The performance of the bioenergy systems was evaluated using previously validated numerical models and the main outputs of the resulting plant were given in terms of electric and thermal power production, avoided $\mathrm{CO}_{2}$ emission and remaining wastes.

The proposed numerical tool was used to evaluate the potential application of an integrated WTE system to the manure available from the animal farming in the province of Modena in Italy. The anaerobic digestion and gasification processes were taken into account as well as a purification system for the liquid part of the digester sludge.

Different scenarios concerning the manure supply chain were analysed ranging from a distributed exploitation of the livestock wastes in each municipality of the province to centralized bioenergy systems located at the centre of the areas grouping several districts.

The results of the numerical code showed that several municipalities in the size of the potential integrated plant were notable and 8 systems resulted in larger than $1 \mathrm{MW}$. Furthermore, the calculations demonstrated that the exploitation of the solid part of the digested manure in the gasifier contributed for approximately the $20 \%$ of the total power production. In addition, the annual electric energy produced from the animal farming manure proved to exceed by $195.7 \%$ the energy requirement of the whole agricultural industry in the province. The integrated plant was also demonstrated to minimize the remaining waste to be disposed, in fact, depending on the initial composition of the manure exploited in each bioenergy system, the remaining amount of waste ranged from 3 to $6 \%$.

Finally, a scenario was considered by grouping the municipalities of the province of Modena into 20 areas in which one plant exploited the manure from the animal farms located in that group. The areas were formed using the proximity of the different municipalities and the resulting size of the plant as guidelines. Using these criteria, it was possible to define 20 plants with an average size of $1 \mathrm{MW}$ with a supposed maximum biomass supply distance of $20 \mathrm{~km}$.

\section{REFERENCES}

1. Eriksson, O. and Bisaillon, M., Multiple System modelling of Waste management, Waste Management, Vol. 31, No. 12, pp 2620-2630, 2011, https://doi.org/10.1016/j.wasman.2011.07.007

2. Hagos, K., Zong, J., Li, D., Liu, C. and Lu, X., Anaerobic Co-digestion Process for Biogas Production: Progress, Challenges and Perspectives, Renewable and Sustainable Energy Reviews, Vol. 76, pp 1485-1496, 2017, https://doi.org/10.1016/j.rser.2016.11.184

3. Sriwannawit, P., Anisa, P. A. and Rony, A. M., Policy impact on Economic viability of Biomass Gasification Systems in Indonesia, Journal of Sustainable Development of Energy, Water and Environment Systems, Vol. 4, No. 1, pp 56-68, 2016, https://doi.org/10.13044/j.sdewes.2016.04.0006 
4. Karagiannidis, A. and Perkoulidis, G., A Multi-criteria ranking of different Technologies for the Anaerobic Digestion for Energy Recovery of the Organic Fraction of Municipal Solid Wastes, Bioresource Technology, Vol. 100, No. 8, pp 2355-2360, 2009, https://doi.org/10.1016/j.biortech.2008.11.033

5. Pena, L., Oliveira, M., Fragoso, R. and Duarte, E., Potential of Duckweed for Swine Wastewater Nutrient removal and Biomass Valorisation through Anaerobic Co-digestion, Journal of Sustainable Development of Energy, Water and Environment Systems, Vol. 5, No. 2, pp 127-138, 2017, https://doi.org/10.13044/j.sdewes.d5.0137

6. Hadin, $\AA$. and Eriksson, O., Horse Manure as Feedstock for Anaerobic Digestion, Waste Management, Vol. 56, pp 506-518, 2016, https://doi.org/10.1016/j.wasman.2016.06.023

7. Dalólio, F. S., Nogueira da Silva, J., Carneiro de Oliveira, A. C., Ferreira Tinôco, I. F., Barbosa, R. C., Resende, M. O., Teixeira Albino, L. F. and Teixeira Coelho, S., Poultry Litter as Biomass Energy: A Review and Future Perspectives, Renewable and Sustainable Energy Reviews, Vol. 76, pp 941-949, 2017, https://doi.org/10.1016/j.rser.2017.03.104

8. Miranda, N. D., Granell, R., Tuomisto, H. L. and McCulloch, M. D., Meta-analysis of Methane Yields from Anaerobic Digestion of Dairy Cattle Manure, Biomass and Bioenergy, Vol. 86, pp 65-75, 2016, https://doi.org/10.1016/j.biombioe.2016.01.012

9. Chen, G., Guo, X., Cheng, Z., Yan, B., Dan, Z. and Ma, W., Air Gasification of Biogas-derived digestate in a Downdraft fixed Bed Gasifier, Waste Management, Vol. 69, pp 162-169, 2017, https://doi.org/10.1016/j.wasman.2017.08.001

10.Nam, H., Maglinao, A. L. Jr., Capareda, S. C. and Rodriguez-Alejandro, D. A., Enriched-air fluidized Bed gasification using Bench and Pilot Scale Reactors of Dairy Manure with Sand bedding based on response Surface methods, Energy, Vol. 95, pp 187-199, 2016, https://doi.org/10.1016/j.energy.2015.11.065

11.León, E. and Martín, M., Optimal production of Power in a combined Cycle from Manure based Biogas, Energy Conversion and Management, Vol. 114, pp 89-99, 2016, https://doi.org/10.1016/j.enconman.2016.02.002

12.Tilche, A. and Galatola, M., The Potential of Bio-methane as Bio-fuel/bio-energy for reducing Greenhouse Gas Emissions: A Qualitative assessment for Europe in a Life Cycle perspective, Water Science and Technology, Vol. 57, No. 11, pp 1683-1692, 2008, https://doi.org/10.2166/wst.2008.039

13.Wu, H., Hanna, M. A. and Jones, D. D., Life Cycle assessment of Greenhouse Gas emissions of Feedlot Manure management Practices: Land Application versus Gasification, Biomass and Bioenergy, Vol. 54, pp 260-266, 2013, https://doi.org/10.1016/j.biombioe.2013.04.011

14.Cantrell, K. B., Ducey, T., Ro, K. S. and Hunt, P. G., Livestock Waste-to-bioenergy Generation opportunities, Bioresource Technology, Vol. 99, No. 17, pp 7941-7953, 2008, https://doi.org/10.1016/j.biortech.2008.02.061

15.Suwelack, K. and Wüst, D., An approach to unify the appraisal Framework for Biomass conversion Systems, Biomass and Bioenergy, Vol. 83, pp 354-365, 2015, https://doi.org/10.1016/j.biombioe.2015.10.012

16.Mitchell, C. P., Development of Decision support Systems for Bioenergy Applications, Biomass and Bioenergy, Vol. 18, No. 4, pp 265-278, 2000, https://doi.org/10.1016/S0961-9534(99)00099-9

17.Wang, J. J., Jing, Y. Y., Zhang, C. F. and Zhao, J. H., Review on Multi-criteria decision analysis Aid in Sustainable Energy decision-making, Renewable and Sustainable Energy Reviews, Vol. 13, No. 9, pp 2263-2278, 2009, https://doi.org/10.1016/j.rser.2009.06.021

18.Strantzali, E. and Aravossis, K., Decision making in Renewable Energy investments: A Review, Renewable and Sustainable Energy Reviews, Vol. 55, pp 885-898, 2016, https://doi.org/10.1016/j.rser.2015.11.021 
19.Bottazzi, D., Farina, S., Milani, M. and Montorsi, L., A Numerical approach for the analysis of the Coffee roasting Process, Journal of Food Engineering, Vol. 112, No. 3, pp 243-252, 2012, https://doi.org/10.1016/j.jfoodeng.2012.04.009

20.Dutra, J. C., Gonzalez-Carmona, M. A., Lazaro-Alvarado, A. F. and Coronas, A., Modeling of a Cogeneration System with a Micro Gas Turbine operating at Partial Load Conditions, Journal of Sustainable Development of Energy, Water and Environment Systems, Vol. 5, No. 2, pp 139-150, 2017, https://doi.org/10.13044/j.sdewes.d5.0138

21.Gaida, D., Wolf, C. and Bongards, M., Feed Control of Anaerobic digestion Processes for Renewable Energy Production: A Review, Renewable and Sustainable Energy Reviews, Vol. 68, Part 2, pp 869-875, 2017, https://doi.org/10.1016/j.rser.2016.06.096

22.Mercati, S., Milani, M., Montorsi, L. and Paltrinieri, F., Optimization of the working Cycle for a Hydrogen production and Power Generation Plant based on Aluminum combustion with Water, International Journal of Hydrogen Energy, Vol. 38, No. 18, pp 7209-7217, 2013, https://doi.org/10.1016/j.ijhydene.2013.04.043

23.Milani, M., Montorsi, L. and Stefani, M., An integrated approach to Energy recovery from Biomass and Waste: Anaerobic Digestion-gasification-water treatment, Waste Management \& Research, Vol. 32, No. 7, pp 614-625, 2014, https://doi.org/10.1177/0734242X14538307

24.Milani, M., Montorsi, L. and Scolari, M., Energy recovery from Waste by means of a Gasification System: Numerical approach, Proceedings of $3^{\text {rd }}$ International Conference on Applied Energy, Perugia, Italy, pp 1555-1568, 2011.

25.Schildt, H., JavaTM Complete Guide ( $8^{\text {th }}$ ed.), McGraw-Hill, Milan, Italy, 2012. 